\title{
Effect of Magnetically Treated Tap Water Quenchant on Hardenability of S45C Steel
}

\author{
T Chucheep $^{a}$, N Mahathaninwong ${ }^{a^{*}}$ (ㄷ, S Janudom ${ }^{b}$, C Sudsiri ${ }^{a}$, S Karrila ${ }^{a}$, W Ketaiam ${ }^{a}$ \\ ${ }^{a}$ Prince of Songkla University, Faculty of Science and Industrial Technology, Surat Thani Campus, \\ Muang, Surat Thani, Thailand. \\ ${ }^{b}$ Prince of Songkla University, Faculty of Engineering, Department of Mining and Materials \\ Engineering, Hat Yai, Songkhla, Thailand.
}

Received: November 01, 2021; Revised: December 28, 2021; Accepted: January 13, 2022

\begin{abstract}
The objective of this work was to investigate effects of magnetically treated tap water quenchant on hardenability and quenching crack resistance of $\mathrm{S} 45 \mathrm{C}$ steel. The magnetically treated water quenchant was prepared by circulating regular tap water though a $130 \mathrm{mT}$ magnetic field. The $\mathrm{S} 45 \mathrm{C}$ steel was austenized at $860^{\circ} \mathrm{C}$ for 30 minutes. The hardenability in transverse section measurement of S45C steel quenched in magnetically treated tap water did not differ from that prepared with regular tap water quenchant. In measurements of the quenched end, the hardenability of S45C Steel quenched in magnetically treated water was below that with tap water quenchant. On the other hand, quenching crack resistance of $\mathrm{S} 45 \mathrm{C}$ steel quenched in magnetically treated tap water was higher than that prepared with regular tap water. Moreover, microstructures of specimens quenched in magnetically treated tap water quenchant were different from that with regular tap water quenchant. Fine martensite structure formed in specimen quenched in regular tap water quenchant, while coarse lath martensite formed in specimens quenched in magnetically treated tap water quenchant.
\end{abstract}

Keywords: Quenchant; Magnetically treated tap water; Tap water; Hardenability; S45C steel

\section{Introduction}

Typically heat treatments of steel parts are needed in the manufacture of automotive components. Most engine components, all parts of gear boxes, axles, drive shafts and suspension parts, as well as steering components and injection systems, are frequently hardened and tempered, or carburized, or nitrocarburized ${ }^{1}$. Hardening of steel includes austenitizing and quenching steps. Austenitizing means heating to about $50^{\circ} \mathrm{C}$ above upper and lower critical temperatures, leading to formation of an austenite phase, when the elevated temperature is held for a proper time. The subsequent rapid cooling by immersion in a quenching medium is called quenching. The microstructure and properties of steel after quenching depends on the choice of quenching medium, such as water, salt solution and oil, which differ in the cooling rates. Water is inexpensive, readily available, and, unless contaminated, it is easily disposed without causing pollution or health hazards. One disadvantage of water is its rapid cooling rate that persists at lower temperatures where distortion and cracking are more likely to occur ${ }^{2}$. Quenching in oil provides slower cooling rates than water quenching, which reduces the possibility of introduction of distortions and cracks in the quenched piece ${ }^{3}$, while the environmental effects of oil waste pose limitations. Finding quenchant alternatives to oils is of interest in related research.

Alternative quenchants have been widely investigated. Wu et al. ${ }^{4}$ developed a water quenchant in electric field, which applied currents to the samples placed in the water. They found

*email : narissara.s@psu.ac.th that the hardness of samples quenched in water with electric field was higher than that quenched in water. The electric field disturbed vapor films covering the hot samples in the first stage of cooling and increased heat transfer rate. On the other hand, quenching in a magnetic field has been studied by adding magnetic particles of $10 \mathrm{~nm}$ diameter into the water quenchant, which also increased hardness of the samples ${ }^{5}$. In addition, Akhbarizadeh et al. ${ }^{6}$ investigated the effects of magnetic field during deep cryogenic treatment at $-195^{\circ} \mathrm{C}$ on the corrosion and wear properties of 1.2080 tool steel grade. The tool steel sample was attracted to a magnet bar during quenching. They found that as the magnetic field was applied, the hardness and the corrosion resistance of the tool steel decreased, while the wear resistance increased. Moreover, Zhang et al. ${ }^{7}$ investigated the effects of high intensity magnetic field on the austenite-to-ferrite transformation in $42 \mathrm{CrMo}$ low alloy steel at different cooling rates. Superconductive magnets were used to generate magnetic field intensities up to $15 \mathrm{~T}$. They reported that the magnetic field accelerated the transformation of austenite to ferrite, increasing the amount of ferrite and pearlite after quenching, while bainite formed in the case without a magnetic field. Prior studies have not investigated the effects on hardenability of steels of water quenchant circulated through a magnetic field.

Effects of a magnetic field on properties of water have been studied, and it can change the electrical conductivity and the evaporation of water ${ }^{8}$. The electrical conductivity and the evaporation of water exposed to magnetic field were higher than without the magnetic field. Viscosity of water decreased with increasing exposure time to a magnetic field ${ }^{9}$. 
When water is circulated through a magnetic field, its surface tension decreases and viscosity increases. Cai et al. ${ }^{10}$ stated that a magnetic field induced hydrogen bonding that led to larger water molecule agglomerates. As flow rate and magnetic field intensity were increased, evaporation and heat transfer of the water increased ${ }^{11}$. Hence, circulating water through a magnetic field can possibility alter its quenchant properties, effectively giving novel control of water quenchants.

Therefore, water quenchant circulated through a static magnetic field was investigated in this study. The feasibility of water quenchant circulation through static magnetic field is evaluated.

\section{Experimental Methods}

\subsection{Preparation of the samples}

$\mathrm{S} 45 \mathrm{C}$ steel was used in test specimens of this work and their chemical composition, shown in Table 1 in weight percentages, was determined by Applied Research Laboratoties-ARL3460 Optical Emission Spectrometry (OES). The dimensions of the as-received S45C were $32 \mathrm{~mm}$ diameter and $1000 \mathrm{~mm}$ length.

The test specimens were machined to cylindrical bar with $32 \mathrm{~mm}$ diameter and $100 \mathrm{~mm}$ length. An S45C steel rod of $13 \mathrm{~mm}$ diameter was cut into $15 \mathrm{~mm}$ long pieces for quenching crack resistance tests.

\subsection{Preparation of magnetically treated water quenchant}

Rectangular NdFeB permanent magnets (100 mm long, $15 \mathrm{~mm}$ wide and $5 \mathrm{~mm}$ thick) were used to provide a static magnetic field, as shown in Figure 1a. Each magnetic piece had a north pole face and opposing south pole face, as shown in Figure 1b. The magnetic flux density was measured at the contact surface for each piece by using a tesla-meter (PHYWE No. 13610-93, Germany), and the magnetic field intensity was not uniform across the contact surface, while its maximum was $130 \mathrm{mT}$. A device to treat tap water magnetically was built based on the apparatus described by Gabrielli et al. ${ }^{12}$, as shown in Figure 1c. It consisted of seven pairs of permanent magnets with north and south poles facing each other, which the distance between magnetic poles on each side being $25 \mathrm{~mm}$ apart. A steel pipe coated with zinc of $1000 \mathrm{~mm}$ length and $25 \mathrm{~mm}$ outer diameter was inserted between the magnets, as shown in Figure 1c. Regular tap water (50 liters) was circulated through the pipe passing between the magnets at a constant 5 liters/min flow rate by a power head pump (Sonic AP1200). In this configuration the magnetic field was perpendicular to the flow of regular tap water. The regular tap water used in this experiment had $\mathrm{pH}$ of about 7.7, total dissolved solid (TDS) of about 32$48 \mathrm{ppm}$, and electrical conductivity of $74 \mu \mathrm{S} / \mathrm{cm}$. The chemical analysis of the regular tap water was examined by Perkin Elmer Optima 8000 Inductively Coupled Plasma-Optical Emission Spectrometer(ICP-OES), from which the results were $10.5 \mathrm{mg} / 1 \mathrm{Cl}, 0.14 \mathrm{mg} / 1 \mathrm{~F},<5 \mathrm{mg} / 1 \mathrm{SO}_{4}, 0.29 \mathrm{mg} / 1 \mathrm{NO}_{3}$, $22.7 \mathrm{mg} / \mathrm{CaCO}_{3}$, and $0.344 \mathrm{mg} / \mathrm{Fe}$, as shown in Table 2 .

\subsection{Hardenability Test}

The S45C specimens of $100 \mathrm{~mm}$ length and $32 \mathrm{~mm}$ diameter were austenized at $860^{\circ} \mathrm{C}$ for 30 minutes and were then removed from the furnace and placed quickly (within $5 \mathrm{~s}$ ) in a rectangular quenching chamber $(25 \mathrm{~cm}$ wide, $25 \mathrm{~cm}$ long, and $25 \mathrm{~cm}$ tall), shown in Figure $2 \mathrm{a}$ and $\mathrm{b}$. Two quenching techniques were applied in the hardenablitity tests. First, the entire specimen was immersed in 9 liters of quenchant

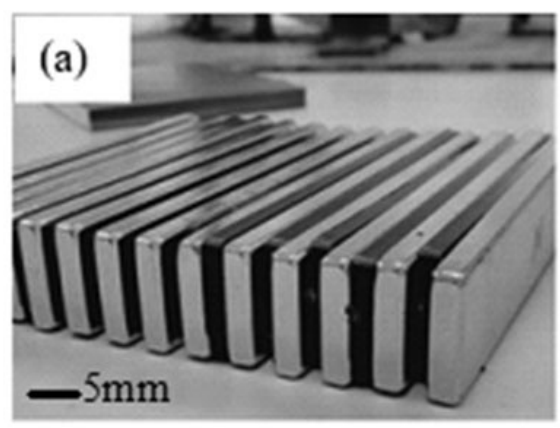

(b)

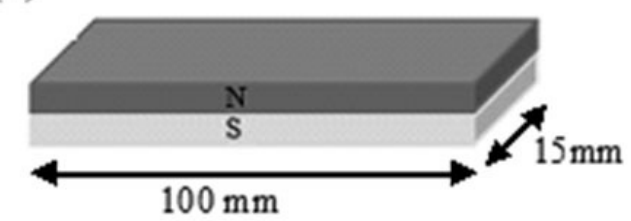

(c)

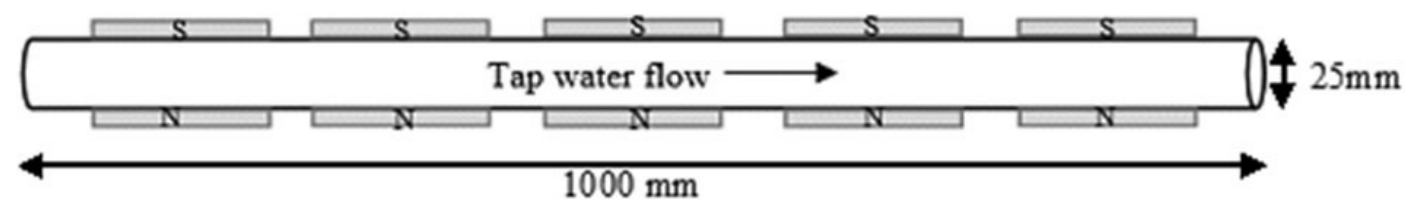

Figure 1. (a) Rectangular NdFeB permanent magnets used in this study, (b) faces of each magnet acting as the poles, and, (c) magnets assembled with a pipe.

Table 1. Chemical composition of S45C Steel

\begin{tabular}{cccccccc}
\hline Element & $\mathrm{C}$ & $\mathrm{Si}$ & $\mathrm{S}$ & $\mathrm{Cu}$ & $\mathrm{Cr}$ & $\mathrm{Mn}$ & $\mathrm{Fe}$ \\
\hline wt. \% & 0.491 & 0.265 & 0.003 & 0.030 & 0.376 & 0.702 & Bal. \\
\hline
\end{tabular}




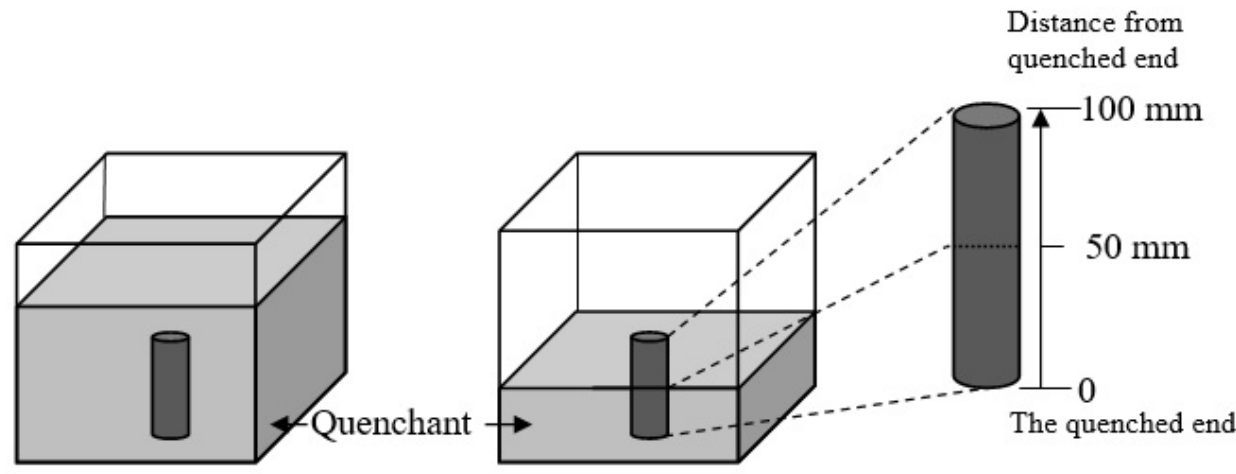

(a)

(b)

Figure 2. (a) quenching of entire specimen by immersion in quenchant (hardness measurement along transverse section), and (b) quenching half a specimen leaving the other half above quenchant (hardness measurement from quenched end)

Table 2. Physicochemical analysis of regular tap water

\begin{tabular}{cc}
\hline Parameters & Regular tap water \\
\hline Electrical conductivity $(\mu \mathrm{S} / \mathrm{cm})$ & 74 \\
\hline $\mathrm{pH}$ & 7.7 \\
\hline $\mathrm{TDS}(\mathrm{ppm})$ & $32-48$ \\
\hline $\mathrm{Cl}(\mathrm{mg} / \mathrm{l})$ & 10.5 \\
\hline $\mathrm{F}(\mathrm{mg} / \mathrm{l})$ & 0.14 \\
\hline $\mathrm{SO}_{4}(\mathrm{mg} / \mathrm{l})$ & $<5$ \\
\hline $\mathrm{NO}_{3}(\mathrm{mg} / \mathrm{l})$ & 0.29 \\
\hline $\mathrm{CaCO}_{3}(\mathrm{mg} / \mathrm{l})$ & 22.7 \\
\hline $\mathrm{Fe}(\mathrm{mg} / \mathrm{l})$ & 0.344
\end{tabular}

for 5 mins, as shown in Figure 2a. The quenched specimen was cut into two pieces at the middle in length direction. The transverse sections of two cut pieces were ground and polished. Rockwell C hardness measurements were made along the transverse sections from the circular boundary to the center.This method is based on the hardenability test of Chen et al. ${ }^{13}$ Second, only half of a sample was immersed in the quenchant for 5 mins, as shown in Figure $2 \mathrm{~b}$. The volume of quenchant in quenching chamber was about 3.125 liters for $50 \mathrm{~mm}$ level height. The quenched specimens were then ground flat to a depth of $0.5 \mathrm{~mm}$ along the entire length of the bar, on two opposing sides. Rockwell $\mathrm{C}$ hardness measurements were made along the length of the bar from quenched end along the two zones: underneath and top surface. Three replicate experiments were run for samples quenched in regular tap water (W); tap water circulated through a magnetic field of $130 \mathrm{mT}$ or magnetically treated tap water (MW); and oil quenchants. The temperatures of water quenchants with or without magnetic treatment were $25.0 \pm 0.5^{\circ} \mathrm{C}$ and oil quenchant was at $32.0 \pm 2.0{ }^{\circ} \mathrm{C}$ before quenching.

\subsection{Quenching cracking resistance test}

For quenching crack resistance measurement based on the paper of Chen et al. ${ }^{13}$, the specimens of $15 \mathrm{~mm}$ length and $13 \mathrm{~mm}$ diameter were heated to $860^{\circ} \mathrm{C}$, held for 15 minutes, and quenched in the alternative quenchants. Austenizing time of this test was shorter than that of the hardenability test due to smaller sized specimen. The temperatures of water quenchants with or without magnetic treatment were $25.0 \pm 0.5^{\circ} \mathrm{C}$ and oil quenchant was at $32.0 \pm 2.0^{\circ} \mathrm{C}$ before quenching. Up to 50 specimens were prepared for each quenchant. After quenching, all the specimens were ground, polished, and etched. A metallographic inspection was then performed. Specimens with quenching cracks were counted and typical look of the cracks was assessed.

\section{Results and Discussion}

\subsection{The effect of magnetic treatment on conductivity of tap water quenchant}

The magnetically treated tap water had increased electrical conductivity from that of tap water without magnetic field treatment and circulation, as shown in Figure 3. The electrical conductivity of MW increased gradually from $74 \mu \mathrm{S} / \mathrm{cm}$ to $83 \mu \mathrm{S} / \mathrm{cm}$ during circulation through static magnetic field over 144 hours. This result matches the investigations of Holysz et al. ${ }^{8}$ and Szczes'et al. ${ }^{11}$ Toledo et al. ${ }^{14}$ found that viscosity, surface tension and vaporization enthalpy increased when water was exposed to magnetic field treatment, and these are correlated with the intermolecular forces. Wang et al. ${ }^{15}$ found that the properties of tap water changed when it was circulated through a magnetic field. The magnetically treated tap water had increased evaporation, with decreased specific heat and boiling point. In addition, magnetic field strength has a marked influence on the physical properties of tap water. The electrical conductivity of regular tap water (W) has no significant change over a similar time frame. The magnetically treated tap water (MW) in this experiment was circulated through the magnetic field for 144 hours.

\subsection{Effect of magnetically treated tap water quenchant on hardenability of S45C steel}

Figure 4 shows the HRC hardness measured on transverse sections at different distances from the circular boundary of the section, when an entire specimen was quenched in 
magnetically treated tap water (MW), regular tap water(W), or in oil quenchant. The hardness of quenched specimen increased at $2 \mathrm{~mm}$ depth from the circular boundary and varied with depth. The hardnesses in the center region were about 34.1 $\pm 3.3 \mathrm{HRC}$ and $31.8 \pm 1.0 \mathrm{HRC}$ for the specimens quenched in the magnetically treated tap water and with regular tap water quenchant, respectively, below those at $2 \mathrm{~mm}$ depth from the circular boundary. At $2 \mathrm{~mm}$ depth from the circular boundary, the average hardness of the specimen after quenching with magnetically treated tap water was $54.0 \pm 2.8 \mathrm{HRC}$, while the average hardness was $51.7 \pm 0.8 \mathrm{HRC}$ after quenching in regular tap water, reaching the result of Chen et al. ${ }^{13}$ They reported that the hardness of \#45 steel quenched in water was over $50 \mathrm{HRC}$ at $2 \mathrm{~mm}$ depth from the surface. This work followed the experiment of Chen et al. ${ }^{13}$, which tested different sample sizes. However, the hardness varied by depth in samples whether quenched in magnetically treated tap water or regular tap water, similarly in both cases. The difference was less than the standard deviation. The specimen quenched in oil did not harden.

For the hardenability test with only half of each specimen immersed in the quenchant (Figure 2b), the quenched specimen was ground to have flat surfaces at a depth of $0.5 \mathrm{~mm}$ from the original cylindrical surface, on two opposing sides. The surface hardness was measured from the quenched end. The surface hardness profiles of S45C steel quenched in regular tap water, magnetically treated tap water, and oil quenchant are shown in Figure 5. After half of specimens were immersed in the quenchants, the average hardnesses at $31 \mathrm{~mm}$ from the quenched end of each specimen were $61.7 \pm 0.7 \mathrm{HRC}$, 56.7 $\pm 1.6 \mathrm{HRC}$ and $19.9 \pm 0.8 \mathrm{HRC}$ for quenching in regular tap water, magnetically treated tap water, and oil quenchant, respectively. The average hardness decreased gradually with distance from end of the specimen, from $31 \mathrm{~mm}$ to $45 \mathrm{~mm}$ distances, and then decreased sharply around the middle of the specimen (at $50 \mathrm{~mm}$ distance from the end) after quenching in regular tap water or in magnetically treated tap water, which were the two quenchants causing hardening. The hardness changed with distance from the quenched end of the specimen. The hardness profles were similar to jominy hardness test profile, as presented by Nunura et al. ${ }^{16}$ and Ghrib et al. ${ }^{17}$ The hardness in upper half of sample above the quenchant decreased gradually with increasing distance (52-81 $\mathrm{mm}$ distance from the quenched end of specimen). The hardness profile of S45C steel quenched in oil changed a little. The hardenability of S45C quenched in magnetically treated tap water tended to be lower than that when using water quenchant. It is possible that the evaporated amount of tap water circulated through magnetic field was higher than without magnetic exposure, as reported by Holys et al. ${ }^{8}$ and Szczes et al. ${ }^{11}$ Faster evaporation may create a vapor blanket that insulates and decreases heat transfer.

The hardness profile of S45C steel in Figure 4 arose from immersing specimen in $\mathrm{W}$ and MW quenchants with heat tranfer in a radial direction, while halfway immersion quenching with heat transfer in longitudinal direction along with air cooling resulted in the hardness profile in Figure 5. The hardness profile varied less in radial direction than in longitudinal direction. However, both hardenability test methods showed no effect from oil quenchant.

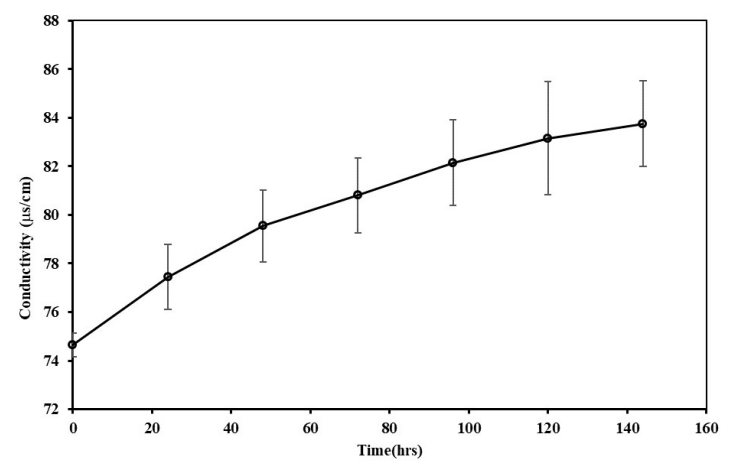

Figure 3. Time profile of electrical conductivity for tap water circulating through the magnetic field (MW).

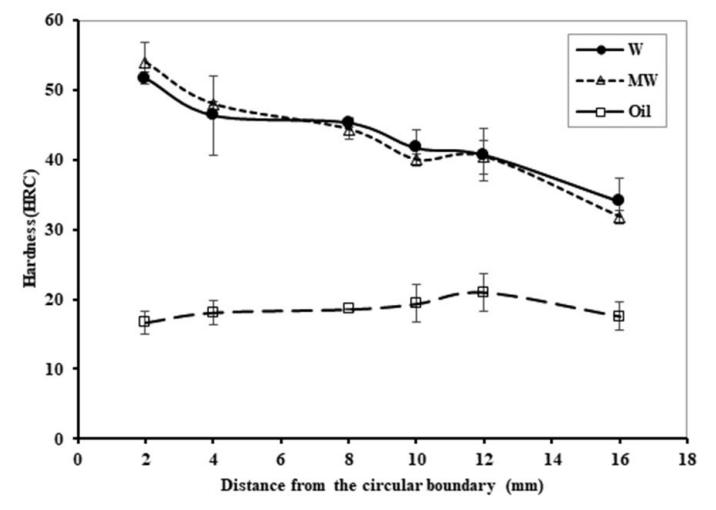

Figure 4. Hardness profiles by distance from circular boundary of specimen quenched in regular tap water (W), magnetically treated tap water (MW), and oil quenchant.

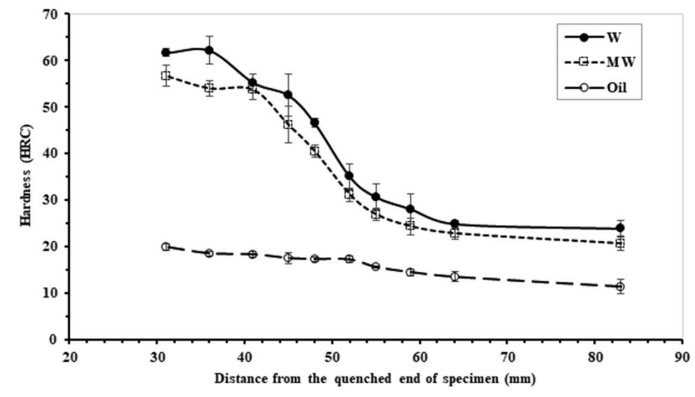

Figure 5. Hardness profiles of S45C steel after quenching only half of each sample by immersing in quenchant: regular tap water(W), magnetically treated tap water (MW), and oil quenchant.

\subsection{Quenching crack resistance}

Table 3 shows the quenching cracking ratios of S45C steel when quenched in the magnetically treated water, water, and oil quenchant. The quenching cracking ratio of S45C steel quenched in magnetically treated tap water (MW) quenchant was $12 \%$, which is obviously less than with regular tap water (W) that gave $26 \%$ quenching cracking ratio. Chen et al. ${ }^{15}$ investigated the quenching cracking 
ratio of \#45 steel quenched in water, and reported $16 \%$ quenching cracking ratio. $25 \%$ quenching cracking ratio of AISI 1045 steel parts with size of 10x10x $55 \mathrm{~mm}$ and a $2 \mathrm{~mm}$ diameter hole through the sample at a distance of $5 \mathrm{~mm}$ from one of the ends has been reported by Canale and Totten ${ }^{18}$. Material type, environment and size/shape of specimen interact in very complex ways affecting the risk of cracking. The S45C steel quenched in water has a higher risk of cracking mainly due to the large stresses incurred by the martensitic transformation ${ }^{15}$. On the other hand, wetting kinematics has a large effect via non-uniform cooling. Film-boiling is unstable and highly variable, and water does not rewet steel in a uniform manner during still quenching, leading to non-uniform cooling ${ }^{19}$. Pang and Deng ${ }^{9}$ found that the wetting angles of magnetized water on the surfaces of hydrophobic materials were decreased from those of fresh water. The surface tension of magnetized water also decreased on comparing with fresh water. Therefore, it is possible that magnetically treated tap water gave more uniform cooling than tap water, resulting in less quenching cracking. Quenching cracking and distortion of steel parts limit the use of water quenchant. Figure $6 a$ and $b$ show the marcro-crack morphologies (pointed out by the black arrows) of specimens quenched in regular tap water and in magnetically treated tap water, respectively. The straight crack propagated in radial direction from the surface towards the core (Figure 6a) obviously, by the caused high quench severity or excessive cooling rates during the quenching ${ }^{20}$. Crack parth of a specimen quenched in magnetically treated tap water (in Figure 6b) was shorter than when quenched in regular tap water. In addition, the cracks formed around fine martensite structures in the specimen quenched in regular tap water (Figure 7a), and a coarser martensite structure was seen in the specimen quenched in magnetically treated tap water (Figure 7b). Three specimens without cracking (after subjecting to the quenching crack resistance test) were selected for hardness measurements. The hardnesses when quenched in regular tap water were 58.0-59.0 HRC, and with

Table 3. Quenching cracking ratio of S45C steel quenched in different quenchants

\begin{tabular}{cccc}
\hline Quenchant & Number of quenching specimens & $\begin{array}{c}\text { Count of specimens with quenching } \\
\text { cracking }\end{array}$ & Quenching cracking ratio (\%) \\
\hline W & 50 & 13 & 26 \\
\hline MW & 50 & 6 & 12 \\
\hline Oil & 50 & None & None \\
\hline
\end{tabular}

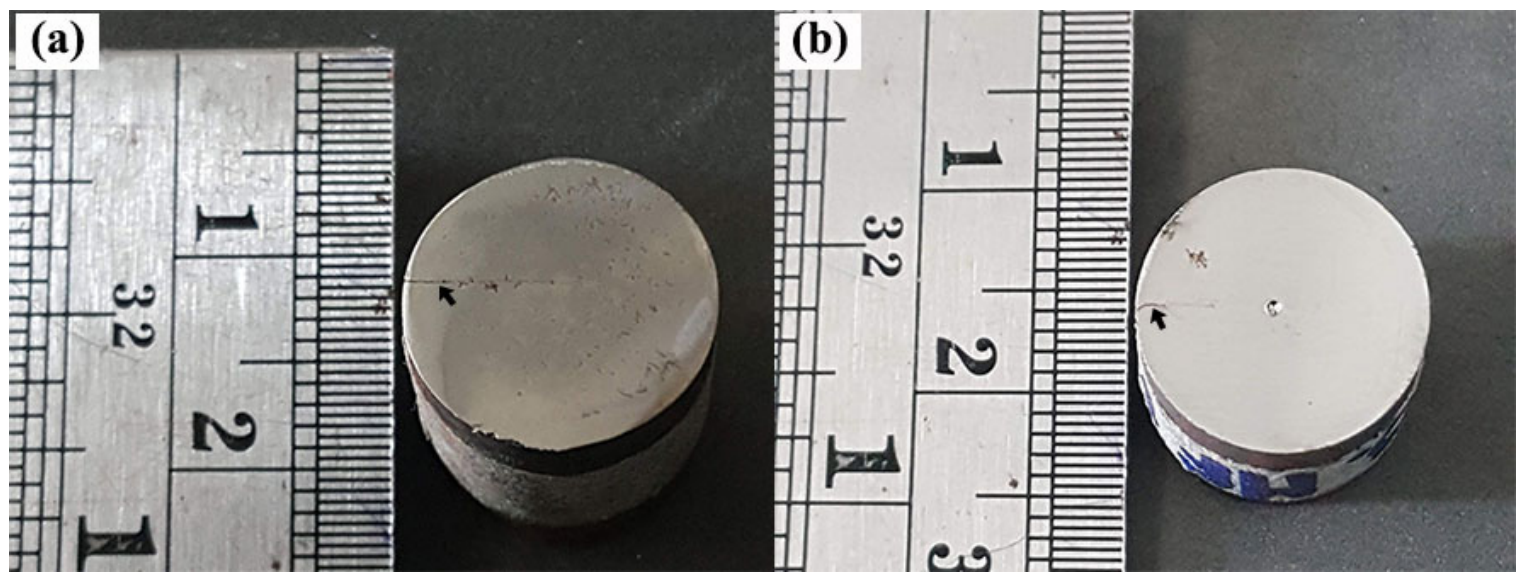

Figure 6. Macro-crack morphology of specimen quenched in (a) regular tap water, and (b) magnetically treated tap water.

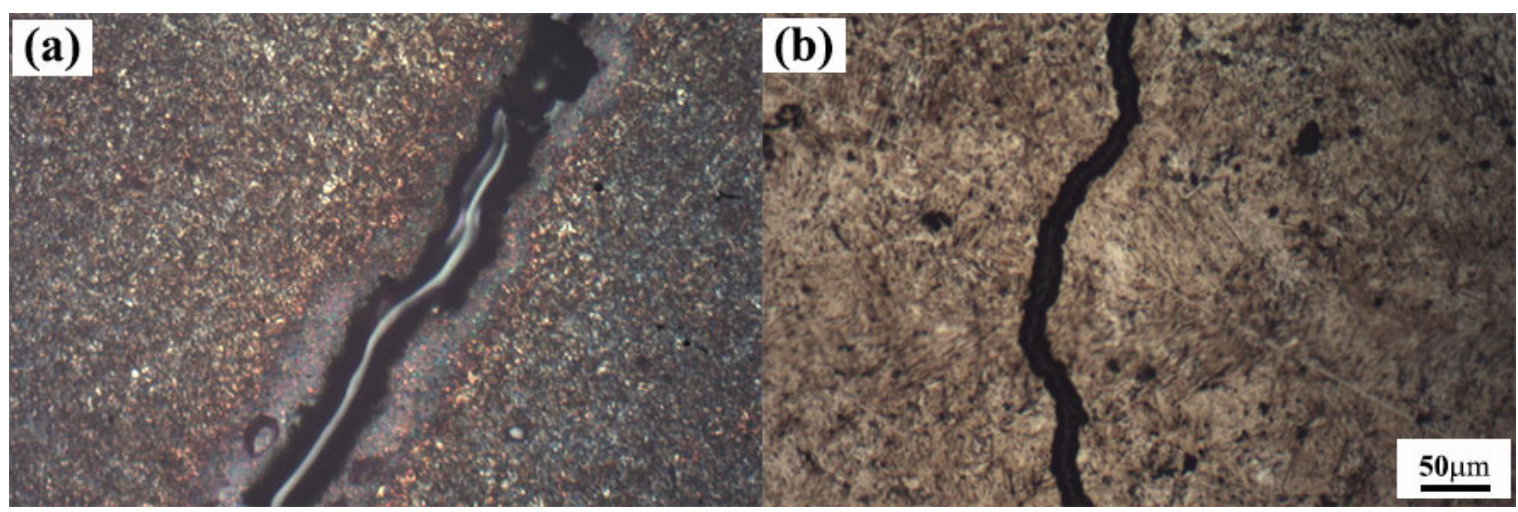

Figure 7. Quenching crack images of specimen quenched in (a) regular tap water, and (b) magnetically treated tap water. 


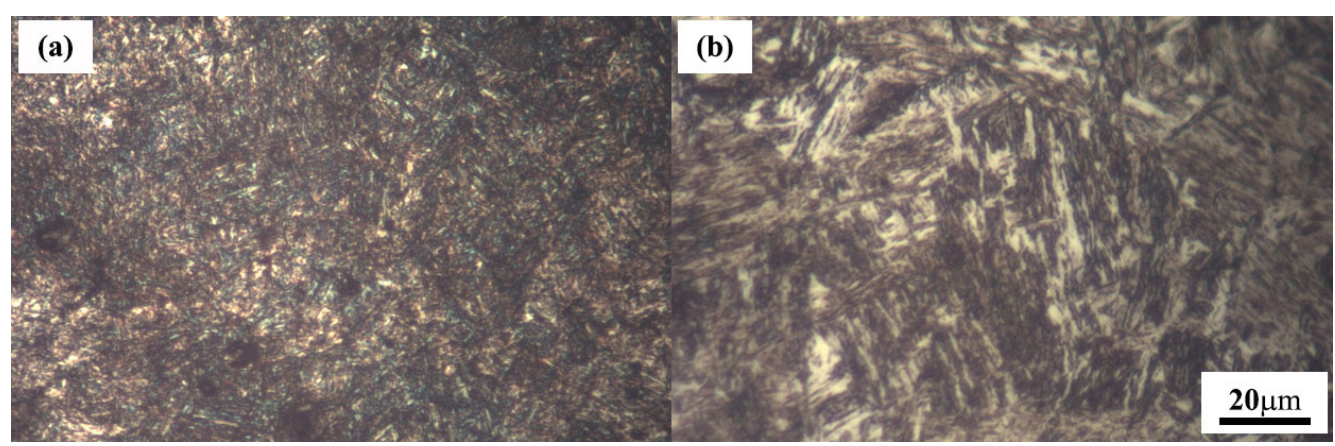

Figure 8. Microstructure of phases in quenching crack resistance specimens after quenching in (a) regular tap water, and (b) magnetically treated tap water.

magnetically treated tap water they were 54.0-56.0 HRC. Quenching in regular tap water gave a fine martensite structure (Figure 8a), with hardness 58-59 HRC. The coarser lath martensite (Figure $8 b$ ) formed in specimen quenched in magnetically treated tap water, decreasing the hardness to $54-56$ HRC.

\section{Conclusions}

Effects of magnetically treated tap water quenchant on hardenability and quenching crack resistance of S45C steel were investigated in this work. The results show that hardenability of S45C steel quenched in magnetically treated tap water as quenchant was similar to that with regular tap water quenchant, in a transverse section measurement. However, the hardenability of S45C steel quenched in magnetically treated water was lower than that with tap water quenchant, around the quenched end of a rod-shaped sample that was quenched with only halfway immersion. Interestingly, quenching crack resistance of S45C steel was higher when quenched in magnetically treated water than with tap water quenchant. Quenching crack ratio of S45C was $12 \%$ with magnetically treated tap water, but $26 \%$ with regular water. The steel quenched in oil had no cracks, as oil quenching also gave no hardening. In addition, microstructures of specimens quenched in magnetically treated tap water were different from those with regular tap water quenchant. A fine martensite structure had formed in specimen quenched in regular tap water, while a coarse lath martensite formed in magnetically treated tap water quenchant. The magnetically treated tap water with increased electrical conductivity could possibly be applied as a quenchant to reduce quenching crack rate from that with regular tap water.

\section{Acknowledgments}

This research was financially supported by Prince of Songkla University, Surat Thani Campus Collaborative Research Fund, 2018 (contract number 004/2561). In addition, this research was also financially supported by Prince of Songkla University, Surat Thani Campus, 2022.

\section{References}

1. Edenhofer B, Lankes HP, Burgmaier H, Kurz A. The flexible heat treatment of automotive components in a novel type of pusher furnace. Metall Ital. 2006;2:39-45.
2. Handbook ASM. Vol. 4 : Heat Treating. Ohio: ASM International; 1991.

3. Rajan TV, Sharma CP. Sharma Ashok. Heat Treatment : Principles \& Techniques. New Delhi: PHI Learning Private Limited; 2011.

4. Wu CW, Liu TX, Ma GJ. Effect of an electric field applied during the quenching on hardness of carbon steel. Mater Sci Eng A. 2008;489:62-4.

5. Chandler H. Heat Treater's Guide: Practices and Procedures for Irons and Steels. Ohio: ASM International; 1995.

6. Akhbarizadeh A, Amini K, Javadpour S. Effects of applying an external magnetic field during the deep cryogenic heat treatment on the corrosion resistance and wear behavior of 1.2080 tool steel. Mater Des. 2012;41:114-23.

7. Zhang Y, He C, Zhao X, Zuo L, Esling C. Thermodynamic and kinetic characteristics of the austenite-to-ferrite transformation under high magnetic field in medium carbon steel. J Magn Magn Mater. 2005;294:267-72.

8. Holysz L, Szczes A, Chibowski E. Effects of a static magnetic field on water and electrolyte solutions. J Colloid Interface Sci. 2007;316:996-1002.

9. Pang XF, Deng B. The changes of macroscopic features and microscopic structures of water under influence of magnetic field. Physica B. 2008;403:3571-7.

10. Cai R, Yang H, He J, Zhu W. The effects of magnetic fields on water molecular hydrogen bonds. J Mol Struct. 2009;938:15-9.

11. Szczes A, Chibowski E, Hołysz L, Rafalski P. Effects of static magnetic field on water at kinetic condition. Chem Eng Process. 2011;50:124-7.

12. Gabrielli C, Jaouharly R, Maurin G, Keddam M. Magnetic water treatment for scale prevention. Water Res. 2001;35:3249-59.

13. Chen X, Zhang L, Jie X, Li Y, Huang X. Quenching characteristics of glycerol solution as a potential new quenchant. Int. J Heat Mass Transf. 2017;109:209-14.

14. Toledo EJL, Ramalho TC, Magriotis ZM. Influence of magnetic field on physical-chemical properties of the liquid water: insights from experimental and theoretical models. J Mol Struct. 2008;888:409-15.

15. Wang Y, Wei H, Li Z. Effect of magnetic field on the physical properties of water. Results Phy. 2018;8:262-7.

16. Nunura CRN, Santos CA, Spim JA. Numerical - Experimental correlation of microstructures, cooling rates and mechanical properties of AISI 1045 steel during the Jominy end-quench test. Mater Des. 2015;76:230-43.

17. Ghrib T, Bejaoui F, Hamdi A, Yacoubi N. Correlation between thermal properties and hardness of end-quench bars for C48, 42CrMo4 and 35NiCrMo16 steels. Thermochim Acta. 2008;473:86-91

18. Canale L CF, Totten GE. Eliminate quench cracking with uniform agitation. Heat Treat Prog. 2004;4:27-30. 
19. Sugianto A, Narazaki M, Kogawara M, Shirayori A. Failure analysis and prevention of quench crack of eccentric holed disk by experimental study and computer simulation. Eng Fail Anal. 2009;16:70-84.
20. Blackwood RR., Jarvis LM, Hoffman DG, Totten GE. Conditions leading to quench cracking other than severity of quench. In: 18th ASM Heat Treating Society Conference and Exposition; 1998; Ohio. Proceedings. Ohio: ASM International; 1998. p. 575-85. 